\title{
Are pre-school girls more likely to be under-nourished in rural Thatta, Pakistan?-a cross-sectional study
}

\author{
Rozina Nuruddin ${ }^{*}$ and Wilbur C. Hadden
}

\begin{abstract}
Background: Pakistan ranks third lowest on a global gender index (2013) and $13^{\text {th }}$ highest on the prevalence of underweight among under-five children (2010). Through this population-based study, we examined gender differentials in the prevalence of stunting, wasting and under-weight defined by World Health Organization (WHO) Growth Standard among rural pre-school Pakistani children.

Methods: We performed secondary analysis of data collected through a cross-sectional survey of Thatta district during 1992-93. Prevalence ratios were calculated for 1051 children aged 0-35 months from 95 randomly selected villages of rural Pakistan using a clustered adjusted log binomial model. Level 1 variables included child and household characteristics and level 2 included village characteristics.

Results: Based on the new WHO growth reference, a major proportion of children were stunted (52.9\%), wasted (22.9\%) and under-weight (46.5\%). In a two-level model, compared to boys, girls had significantly greater risk of stunting [Prevalence Ratio (PR) $(95 \%$ C.I.) $=1.18(1.03,1.36)]$ and under-weight [P.R. (95 \% C.I.) $1.14(1.03,1.26)]$, after adjustment of maternal literacy and village variables. Risk of wasting did not differ with gender [P.R. (95\% C.I.) = $1.04(0.99,1.15)]$. Mothers of stunted and underweight children were respectively, 21 and $20 \%$ more likely to be illiterate than those of normally nourished children. Sick children were at $16 \%$ greater risk of wasting than those not reported ill.

Conclusion: Greater prevalence of stunting and under-weight among girls suggests adoption of a gender sensitive approach in nutritional intervention programmes. Prompt management of childhood illnesses may reduce prevalence of wasting. Better literacy among rural mothers may reduce prevalence of stunting and under-weight. Whether gender differences in nutrition status are an underlying pathway for excessive girl mortality in rural Thatta needs further examination.
\end{abstract}

Keywords: Preschool children, Gender, Under-nutrition, Pakistan, WHO growth reference

\section{Background}

Under nutrition is a major modifiable determinant of child survival, health [1, 2], growth and development [3]. However, it continues to be a major public health problem in most developing countries. More than half of the world's undernourished children are found in just three countries (India (39\%), Bangladesh (5.7 \%) and Pakistan (5.5\%) [4]. Pakistan ranks 57 out of 76 countries on the global hunger index (based on population under

\footnotetext{
* Correspondence: rozina.nuruddin@aku.edu

Department of Community Health Sciences, Aga Khan University, Stadium Road, P.O. Box 3500, Karachi 74800, Pakistan
}

nourishment, child underweight and child mortality) [5]. Its recent estimates of underweight, wasting and stunting for under-five Pakistani children are 31.6, 10.5 and $45 \%$, respectively [6]. Further, these estimates are higher for rural $(33.3,16.1$ and $46.3 \%)$ than for urban population (26.6, 12.7 and $36.9 \%$ ) [7]. Of concern is worsening status of stunting between 1990-99 estimates (42.7\%) [8] and 2012-13 estimates (45\%) [6].

Gender differences in nutritional status are of concern mainly in settings where girls are considered less important than boys [9]. On a global gender index (based on four fundamental categories of economic participation and 
opportunity, educational attainment, health and survival and political empowerment), Pakistan ranking is dropped from third lowest out of 135 countries in 2011 [10] to second lowest out of 142 countries in 2014 [11]. Evidence about gender difference in undernutrition among Pakistani children however, is scant and conflicting. Girl disadvantge in nutritional status is reported in eight urban squatter settlements of Karachi [12], boy disadvantage in 300 rural and urban communities included in the Pakistan Integrated Household Survey (PIHS) (1991) [13] and no gender difference in four rural districts of Sindh [14]. These findings did not account for contextual community level factors in analysis. In addition, they were based on nutritional status of children defined by 1977 NCHS growth reference, the suitability of which as a growth reference has been criticized on serious technical grounds $[15,16]$. The new WHO growth reference released in April 2006 is recommended for use in preference to the NCHS reference to assess children regardless of ethnicity, socio-economic status and type of feeding [17]. It gives greater prevalence of stunting throughout childhood, of wasting during infancy and of under-weight during first half of infancy $[18,19]$. Pakistan is reported to use combined NCHS/WHO growth reference, combined growth charts for males and females and z-score or standard deviation system rather than percentiles [20]. However, gender differential in nutritional status of pre-school rural Pakistani children has not been assessed based on new World Health Organization (WHO) growth reference.

The conceptual frameworks proposed by Mosley and Chen [21] and by UNICEF [22] describe gender as a determinant of dietary intake (a proximate determinant) based on cultural and societal values. The UNICEF framework [21] identifies inadequate dietary intake and disease as immediate causes of under-nutrition, food security, care of women and children, health services and environment as underlying causes, and economic and political structures as basic determinants of undernutrition. In this study, we grouped our variables into two instead of three levels of UNICEF framework as follows; (i) underlying or intermediate level determinants that relate to the community and consist of village factors and (ii) immediate or proximal level determinants that relate to the individual and consist of child, maternal and household characteristics (Fig. 1).

We primarily aimed to examine the association of gender separately with stunting (reflecting chronic undernutrition), wasting (reflecting acute under-nutrition) and under-weight (reflecting synthesis of acute and chronic under-nutrition) among pre-school rural Pakistani children in specific conceptual and analytical frameworks. Through a two-level logistic regression model, we tested the null hypothesis that child nutritional status was not influenced by gender.

\section{Methods}

\section{Study setting, design, data source and participants}

Thatta is a predominantly rural district of Sindh province located $60 \mathrm{~km}$ east of Karachi inhabited by a predominantly Muslim and Sindhi speaking population [23, 24] of about 1.1 million [25]. Its growth rate is 2.26 with an average household size of 5.1 and dependancy ratio of 87.9 [25]. With an under five mortality rate of $129 /$ 1000 live births and with $49 \%$ of its under-five children underweight, its health indicators are the worst of 16 districts of the Sindh province [26]. Its developmental indicators are also poor such as $35 \%$ adult ( $\geq 15$ years) literacy level [27] and access to piped water for only 16$17 \%$ of the popualtion [26, 27]. The death rate among girls is also relatively higher than among boys during postnatal period and in the 12-59 months age group [28]. The adult sex ratio in Thatta $(112 \mathrm{M}: 100 \mathrm{~F})$ is greatly baised towards males [29].

The data analysed for this cross-sectional study are derived from a larger survey conducted by the Aga Khan University, Karachi during November 1992 and February 1993 in Thatta, a rural district of Sindh Province of Pakistan. This survey provided baseline information on heath and nutrition status of the population and use of government health services to be used in evaluating a health system improvement project [23, 24]. Information was collected at the village, household and individual levels and provided relevant measures of our conceptual framework. The more recent Pakistan Demographic Health Survey (2012-13) lacks information about village development such as access to health facilities and availability of girls' schools, maternal health status and ageadjusted feeding status of children [30]. Moreover, our data though collected more than two decades ago are still relevant as Thatta has not shown significant improvement in health and developmental indicators over time. According to UNICEF, Thatta was categorized as a district with low Human Development Index [26]. Its child health indicators have worsened over time as shown by under-five mortality rate /1000 live births of 108 in 1992-93 [31] and 129 in 2003-04 [26], infant mortality rate/1000 live births of 78 in 1992-93 [31] and 91 in 2003-04 [26] and underweight prevalence of $48 \%$ for children under three in 1992-93 [18] and of $49 \%$ for children under five in 2003-04 [26]. Its progress on development indicators is also not impressive such as an adult ( $>15$ years) literacy level of $32 \%$ in 1992-93 [23] and $35 \%$ in 2012-13 [27] and concrete housing for $17 \%$ of population in 1992-93 [31] and $19 \%$ in 2004-05 [32].

A three-staged stratified random cluster sampling technique was adopted. First, union councils (UCs) were identified that served as strata. Second, villages were 


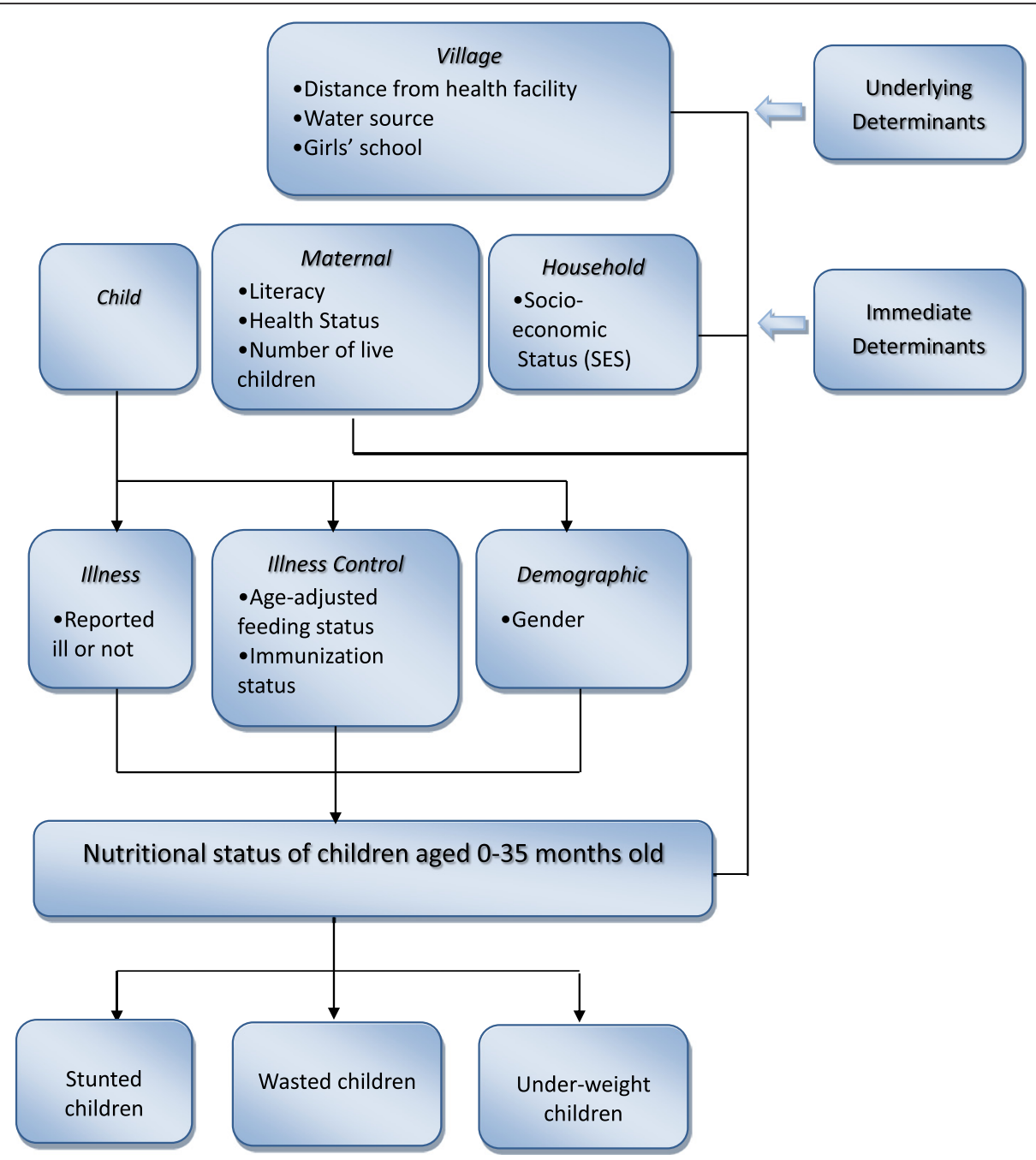

Fig. 1 Conceptual framework of association between child's nutritional status and gender

identified that served as clusters or sampling units. Third, households within selected villages were surveyed to provide information about population elements. From a total of 24 Union Councils (UC), 12 with fairly complete enumeration lists were identified. Due to eccentric location of some of the government health facilities (GHF) within a $\mathrm{UC}$, a $5 \mathrm{~km}$ radius around them was drawn. Villages (Primary Sampling Units) located within this radius were listed and mapped. From the available list of villages, through computer-generated random numbers, five to twelve villages were selected from each service area, with a target to sample at least 250 households per GHF catchment area. Only households having at least one child less than five years of age were surveyed. In this way, a population of 24,121 subjects from 2,276 households and ninety-nine villages were surveyed, giving an average of 23 households per village. Non-response rate was $9 \%$ for overall survey and $30 \%$ for anthropometric examination of children aged 0-35 months. In this way, from 952 households and 95 villages, 1051 children participated in anthropometric examination and were included in the study [18]. This was more than desired sample of 922 children based on assumption of an annual crude birth rate of 36/ 1000 population and a $40 \%$ prevalence of underweight among children aged 0-35 months [24], an $\alpha$ error of $5 \%$, a desired precision of $5 \%$ and a design effect of 2.5 [33].

\section{Data collection}

An elaborate pre-coded survey questionnaire designed for a face-to-face interview was pre-tested after approval from an institutional ethical committee. A validation survey of 400 households was conducted within two weeks of the actual survey for determination of data collection errors [24]. Informed consent was obtained from village headmen and heads of hosueholds to provide information about relevant sections of the questionnaire. 
Mothers were approached to provide active constent regarding child anthropometric examniation.

Village headmen provided information for a village profile including water source and presence of girls' school. Village distance by the shortest possible road route to the nearest health facility was measured (in kilometres) using a vehicle odometer.

Heads of households provided information about three indicators of household socio-economic status (SES) (i.e. type of house, land ownership and per capita average monthly household income, later divided at its median) which were combined to create a single measure. Subjects were grouped as low, middle or upper SES if all three, any two or at most one of three indicators reflected economic disadvantage.

Mothers were asked about their literacy status (ability to read and/or write a short simple statement) and number of live children. Their health status during the year preceding the interview was assessed through a series of questions about illness symptoms lasting for $>2$ weeks. They also provided information about their children. This included age determined with the aid of a calendar listing important local events, festivals and moon cycles in the last five years, any illness during the last one year, age at weaning and immunization status (assessed by immunization card when available or from mother).

Trained field workers took anthropometric measurements of children under three years of age. Childrens' weight was recorded to the nearest $0.1 \mathrm{~kg}$ using portable
$25 \mathrm{~kg}$ spring balance Salter Scales (Salter England, West Bromwich, UK). Weighing scales were calibrated daily using $20 \mathrm{~kg}$ weights. Standard weighing procedures were followed. Children were lightly clad and without shoes/ slippers. Recumbent length (for children less than 24 months) was measured to the nearest centimetre with portable flat wooden boards with sliding foot pieces (locally manufactured by Pakistan Medical and Dental Council). For children older than 24 months, standing height was obtained. Severely malnourished children were referred to a local hospital or a health centre for further assessment and care.

Completed questionnaires were checked and validated by field supervisors daily. Questionnaires with inconsistencies were re-sent to the field for correction. Data quality was maintained by supervision and retraining of the field staff.

Categorization of the study variables is listed in table 1.

\section{Data analysis}

Measured heights and weights were converted to standard normal scores (Z-scores) on the WHO standard distributions adjusting for child's age and gender with a software package named ANTHRO (available at http:// www.who.int/nutgrowthdb). Our Z-score standard deviations were close to 1 , suggesting reasonable quality of the measures [34].

To account for unequal selection probabilities and to reduce bias in variance estimation, weights were calculated

Table 1 Description of study variables and their categorization

\begin{tabular}{|c|c|}
\hline Independent variables & Categories $^{\mathrm{a}}$ \\
\hline \multicolumn{2}{|l|}{ Child characteristics } \\
\hline Gender & Girl or boy \\
\hline Age-adjusted feeding status & $\begin{array}{l}\text { - Aged } \geq 12 \text { months and on regular diet } \\
\text { - Aged } 7-11 \text { months and weaned at or after } \\
7 \text { months } \\
\text { - Aged 5-11 months and weaned at 5-6 months } \\
\text { - Nursing infants aged 0-6 months }\end{array}$ \\
\hline Immunization status & Incomplete/none or complete/ appropriate. \\
\hline Reported ill during one year period & Yes or no \\
\hline \multicolumn{2}{|l|}{ Maternal and household characteristics } \\
\hline Maternal literacy & Illiterate or literate \\
\hline Number of live children & $\geq 4$ or $\leq 3$ \\
\hline Poor maternal health & Yes or no \\
\hline $\begin{array}{l}\text { Household socio-economic status (SES)(House type, land } \\
\text { ownership, income) }\end{array}$ & Low, middle or upper \\
\hline \multicolumn{2}{|l|}{ Village characteristics } \\
\hline Distance from the nearest health facility & $>3$ or $\leq 3 \mathrm{~km}$ \\
\hline Water source & Non-piped (well, pond, canal or river) or piped \\
\hline A girls' school. & Absent or present \\
\hline
\end{tabular}

a Last category is the reference category for all variables 
as the inverse of the sample selection probabilities. We present weighted prevalence of under-nutrition with their $95 \%$ confidence intervals. Prevalence of under-nutrition (percentage of children aged 0-35 months) was calculated following convention [35] as the number of children with Z-scores less than 2 SD below the WHO standard for nutritional parameters wasting (weight-for-height), stunting (height-for-age) and underweight (weight-for-age). Mild, moderate and severe malnutrition were determined using the relevant parameters of the reference population as below -1 and down to $-2 \mathrm{SD}$, below -2 and down to -3 $\mathrm{SD}$ and below $-3 \mathrm{SD}$, respectively. Mean Z-scores (and their SD) for under-nutrition were calculated to compare with the WHO standard.

Since this study was a part of the larger survey, subjects who met the criteria for this study were identified from the database and the post-hoc power calculations were done assuming an $\alpha$ error of 0.05 , a design effect of 2 and $20 \%$ greater under-nutrition among girls than among boys. The post hoc power for detecting gender difference in prevalence of stunting, wasting and under-weight, respectively was found to be 74, 90 and $94 \%$. As under-nutrition is a relatively common outcome measure (with a prevalence of $>10 \%$ ), we calculated adjusted prevalence ratios [36] using SAS Proc Genmod [37] with the binomial distribution and the log-link function [38]. We adopted COPY method when the log-binomial model did not converge [39].

Clustering at the village level was accounted for by the use of a cluster identitfier for village level variables in a repeated statement using Proc Genmod. We did not account for clustering at household or maternal level as there was only one child less than 35 months per household and per mother in 90 and $92 \%$ respectively of the surveyed households. Hence, our level-1 (micro-level) variables were child, maternal and household factors and level-2 (macro-level) variables were village factors.

Five multivariate models were estimated for each nutritional status variable as follows: (i) gender and village variables; (ii) village variables only; (iii) child and village variables; (iv) gender, household and village variables; and (v) gender and village variables along with those child and household variables identified in crude and model 3 or 4 analyses. In the final model, gender and village variables were retained and the variable with the smallest $p$-value $(<0.05)$ was entered first, followed by the addition of one variable at a time, retaining ones with $p$-value $\leq 0.05$ and removing ones with $p$-value $>$ 0.05 . We present the results of generalized estimating equations from the final model.

\section{Results and discussion}

\section{Characteristics of the study population}

There were fewer girls than boys. Nursing infants (0-6 months) constituted $21.3 \%$ of the subjects. Based on the new WHO growth reference, a significant proportion of children were stunted (52.9\%), wasted (22.9\%) and under-weight (46.5\%) (Table 2). More than half had not received any immunization and about a quarter received incomplete immunization as reported by mothers or documented in the immunization card ( $38.8 \%$ of children). About one fifth $(18.0 \%)$ of the children were reported ill over a one year period.

Most of the mothers were illiterate $(83.7 \%)$ and had four or more living children $(52.5 \%)$. One-fifth of them $(21.9 \%)$ reported poor health. Households with low, middle and high SES consitituted 27.6, 48.8 and $23.6 \%$ of the population, respectively. Most villages were three or more kilometres away from the nearest government health facility (55.4\%), had a non-piped water source (89.9\%) and no girls' school (82.9\%).

\section{Risk factors for under-nutrition (un-adjusted analysis)}

In univariate analyses, risk of stunting was greater for girls (by $19 \%$ ) and for children of illiterate mothers (by $25 \%$ ) (Table 3). Wasting was not significantly associated with gender. However, its risk was $17 \%$ greater among children reported sick. Risk of under-weight was greater for girls (by $13 \%$ ), if mother was illiterate (by $25 \%$ ) and if water source was non-piped (by $20 \%$ ).

\section{Gender and under-nutrition (a two-level analysis)}

Compared to boys, girls had 18 and $14 \%$ greater risk of stunting and under-weight, respectively, after adjustment of maternal literacy and village variables (Table 4). Similarly, children with illiterate mothers were at 21 and $20 \%$ greater risk of being stunted and under-weight respectively than literate mothers after accounting for child's gender and village variables.

Gender was not a significant predictor of wasting when adjustment was made for child illness and village variables. However, sick children were at $16 \%$ greater risk of wasting than those not reported ill after accounting for child's gender and village variables.

All contextual factors had a null effect on stunting, wasting and under-weight. Overall, village variables contributed little to explain variability in child's nutritional status.

\section{Discussion}

Based on Millennium Development Goal 1 (MDG1) (halving the prevalence of underweight from $40 \%$ in 1990 to $<20 \%$ in 2015 among under-five children), Pakistan's progress (31.5\% in 2013) is off the track [40]. Compared to other provinces that are showing declining trends, there is negligible progress on MDG1 for Sindh province where Thatta district is located [40].

This study supports the existence of girl disadvantage in child nutrition in Thatta district. Higher prevalence of 
Table 2 Child characteristics $(n=1051)$

\begin{tabular}{lc}
\hline Variables & Per cent (weighted) \\
\hline Stunted children & 52.9 \\
Wasted children & 22.9 \\
Under-weight children & 46.5 \\
Female & 47.0 \\
Age-adjusted feeding status & 21.311 .010 .057 .7 \\
- Nursing infants (0-6 months of age) & \\
- Infants aged 5-11 months and weaned at 5-6 months & \\
- Early childhood ( $\geq 12$ months of age) & at or after 7 months \\
None or incomplete immunized children & 79.7 \\
Children reported ill & 18.0 \\
\hline
\end{tabular}

stunting (by $18 \%$ ) and under-weight (by $14 \%$ ) among girls than boys suggests examining a possible role of under-nutrition as an underlying pathway for excessive girl mortality. These findings are in contrast to the recent reports of Pakistan Demographic and Health Survey (PDHS) (2012-2013) [30] which shows greater prevalence of stunting, wasting and under-weight among boys than among girls under 5 years of age. Though, PDHS uses WHO growth standard as the reference, these national figures do not simultaneously adjust for gender and other variables including age.

However, our findings are consistent with those observed in Bangladesh [41] where WHO growth reference was used to study the gender difference in height for age and where girls showed greater growth faltering than boys after 23 months of age. Association of gender with stunting observed in our study is weaker compared to that reported by Baig et al [12] for urban squatter settlements of Karachi. This could be because of the use of a different growth reference [42]. Irrespective of gender, use of WHO growth reference has been reported to detect stunting better among children and to detect underweight and wasting better among young infants $[18,19]$. In reality, the prevalence of under-nutrition among girls could be more than that observed since anthropometric measurements were done only for surviving children,

Table 3 Crude prevalence ratios for under-nutrition (confidence intervals adjusted for clustered design)

\begin{tabular}{|c|c|c|c|}
\hline \multirow[t]{2}{*}{ Variables } & \multicolumn{3}{|c|}{ Crude prevalence ratios (95 \% C.I.) } \\
\hline & Stunting & Wasting & Under-weight \\
\hline \multicolumn{4}{|l|}{ Child characteristics } \\
\hline Female & $1.19(1.03,1.37)$ & $1.05(0.99,1.12)$ & $1.13(1.02,1.27)$ \\
\hline Early childhood ${ }^{a}$ & $0.89(0.76,1.04)$ & $1.04(0.95,1.13)$ & $1.07(0.89,1.27)$ \\
\hline Infants weaned late ${ }^{a}$ & $0.88(0.69,1.11)$ & $0.98(0.88,1.09)$ & $0.97(0.72,1.31)$ \\
\hline Infants weaned early ${ }^{a}$ & $0.99(0.82,1.20)$ & $0.93(0.81,1.06)$ & $1.02(0.79,1.30)$ \\
\hline None/incomplete immunization & $1.01(0.84,1.22)$ & $0.96(0.87,1.07)$ & $0.88(0.76,1.02)$ \\
\hline Reported ill & $0.95(0.79,1.15)$ & $1.17(1.05,1.31)$ & $0.83(0.65,1.06)$ \\
\hline \multicolumn{4}{|l|}{ Maternal and Household characteristics } \\
\hline Illiterate mother & $1.25(1.03,1.52)$ & $0.99(0.91,1.07)$ & $1.25(1.06,1.47)$ \\
\hline$\geq 4$ live children & $0.98(0.85,1.14)$ & $1.01(0.94,1.09)$ & $1.01(0.88,1.16)$ \\
\hline Poor maternal health & $0.98(0.83,1.15)$ & $1.05(0.97,1.13)$ & $1.04(0.91,1.18)$ \\
\hline Households of low SES ${ }^{b}$ & $1.05(0.89,1.24)$ & $1.04(0.93,1.14)$ & $0.95(0.78,1.14)$ \\
\hline Households of middle SES ${ }^{b}$ & $1.03(0.87,1.23)$ & $1.07(0.98,1.17)$ & $1.10(0.94,1.29)$ \\
\hline \multicolumn{4}{|l|}{ Village characteristics } \\
\hline Health facility at $\geq 3 \mathrm{~km}$ & $0.86(0.71,1.03)$ & $1.01(0.94,1.09)$ & $0.87(0.74,1.03)$ \\
\hline Non-piped water supply & $0.84(0.67,1.06)$ & $0.93(0.86,1.01)$ & $1.20(1.01,1.43)$ \\
\hline No girls' school & $0.96(0.75,1.22)$ & $0.99(0.90,1.09)$ & $0.99(0.79,1.23)$ \\
\hline
\end{tabular}

${ }^{a}$ Reference category is nursing infants

${ }^{b}$ Reference category is households of high SES 
Table 4 Under nutrition and gender: adjusted prevalence ratios (95\% Cl)

\begin{tabular}{|c|c|c|c|}
\hline \multirow[t]{2}{*}{ Variables } & \multicolumn{3}{|c|}{ Adjusted prevalence ratio (95 \% C.I.) } \\
\hline & Stunting & Wasting & Underweight \\
\hline \multicolumn{4}{|l|}{ Child characteristics } \\
\hline Female & $1.18(1.03,1.36)$ & $1.04(0.99,1.15)$ & $1.14(1.03,1.26)$ \\
\hline Early childhood ${ }^{a}$ & - & - & - \\
\hline Infants weaned early ${ }^{a}$ & - & - & - \\
\hline Infants weaned late ${ }^{a}$ & - & - & - \\
\hline None/incomplete immunization & - & - & - \\
\hline Reported ill & - & $1.16(1.04,1.30)$ & - \\
\hline \multicolumn{4}{|l|}{ Maternal and household characteristics } \\
\hline Illiterate mother & $1.21(1.01,1.46)$ & - & $1.20(1.02,1.41)$ \\
\hline$\geq 4$ live children & - & - & - \\
\hline Poor maternal health & - & - & - \\
\hline LOW SES ${ }^{b}$ & - & - & - \\
\hline Middle SES b & - & - & - \\
\hline \multicolumn{4}{|l|}{ Village characteristics } \\
\hline Health facility at $\geq 3$ km & $0.91(0.77,1.07)$ & $1.04(0.96,1.11)$ & $0.93(0.79,1.09)$ \\
\hline Non-piped water supply & $1.14(0.92,1.41)$ & $1.07(0.98,1.16)$ & $1.15(0.98,1.35)$ \\
\hline No girls' school & $0.97(0.79,1.18)$ & $0.98(0.90,1.07)$ & $1.02(0.86,1.21)$ \\
\hline Log Likelihood & -680.73 & -530.34 & -679.70 \\
\hline R-Square ${ }^{c}$ & 0.009 & 0.004 & 0.008 \\
\hline
\end{tabular}

${ }^{a}$ Reference category is nursing infants

${ }^{\mathrm{b}}$ Reference category is households of high SES

c Max-Rescaled Generalized R-Square

leaving better nourished girls to be measured and excluding those who died of severe under-nutrition [43].

This study provides additional evidence associating child's illness and maternal illiteracy with undernutrition. Increased risk of wasting with child's illness suggests association of acute under-nutrition with severe infections [44]. Maternal literacy may influence stunting and under-weight through better management of household resources, better weaning and feeding practices and improved health knowledge and behaviour $[45,46]$.

Although water source showed an association with wasting and under-weight in one of the preliminary models, it lost its significance later in the final model. This could in part be due to the fact that access to improved water source does not, on its own, ensure improved health. It is its correct use through hygienic behaviour such as washing hands with soap after defecating and before eating and safe handling while preparing food and storage of water that leads to improved health $[47,48]$.

Evidence regarding a gender differential in nutritional status in South Asia is scant compared to evidence regarding a gender differential in health care seeking. Most of the available evidence does not support the existence of female disadvantage in nutritional status, despite strong son preference in South Asia [14, 49, 50] except for a few studies that suggest female disadvantage in nutritional status [12, 51]. Important determinants of such discrimination against girls include lower socioeconomic status [52], older siblings of similar gender [53] and birth order [9]. In all these studies however, the nutritional status of children was not based on the new WHO growth standard, odds ratio was the measure of effect reported and analysis did not account for contextual community factors.

\section{Strengths and limitations}

Our study is unique in that its conclusions are based on the most appropriate measure of association (prevalence ratio) suitable for common outcome measures such as child under-nutrition. Studies based on odds ratios in such circumstances tend to overestimate common outcomes [36]. In this study, we also take account of cluster correlation. Further, nutritional status is defined based on the recent WHO growth standard. Assessment of gender differentials in nutritional status in a fairly comprehensive conceptual framework suggests that a greater proportion of girls are stunted and wasted compared to boys in the rural district of Thatta with significant influence of maternal illiteracy on nutritional status. 
Since the survey was conducted during a dry winter period before the harvest season, low access to food might have accounted for high levels of under-nutrition. A certain degree of misclassification could not be excluded particularly for variables based on self-report such as child's age, household income, maternal health status and child feeding, immunization and health status. There is however, a close relationship between prevalence of stunting and underweight obtained from computed ages and by ages rounded to the nearest month [54]. Non-availability of anthropometric information for $30 \%$ of the subjects is almost similar to the missing values reported for more than $25 \%$ of population in UNICEF, district-based Multiple Indicator Cluster Survey [26]. Though, age, gender, mean household income per capita and maternal education did not differ significantly by response status [18], it is likely that those who did not participate could be ill and under-nourished. Despite low study power (74 \%) to detect the gender differential in stunting, we were able to detect it.

Selected UC were those that had enumerated village list reflecting their better administrative capacity compared to those where complete village list was not available. This could have resulted in exclusion of UC with worse health and developmental indicators. Similarly, selection of villages located within $5 \mathrm{kms}$ radius distance from GHF because of convenience could reflect inclusion of better off villages and could affect generalizability of the results. In addition, we were unable to account for other important determinants of nutritional status such as mother's anthropometry, child's birth weight and birth order, sibling gender and birth interval due to lack of such information in our dataset.

\section{Conclusions}

Greater prevalence of stunting and under-weight among girls suggests that a gender sensitive approach should be adopted in nutritional intervention programmes. Communities, governmental and non-govenrmental organizations should be sensitized towards the long term and inter-generational consequences of girl malnutrition on delivery complications such as obstructed labour due to short pelvis or birth of small babies. Similarly, children with reported illnesses and whose mothers are illiterate constitute high risk groups for nutritional advice. Prompt management of childhood illnesses may reduce prevalence of wasting and improvement of maternal literacy among rural mothers may reduce prevalence of stunting and under-weight.

Exploration of gender differences in nutrition status should consider follow-up of a birth cohort to address the concerns of age misreporting and survivor bias and to permit inclusion of information about maternal anthropometry, child's birth weight, birth interval, birth order and sibling gender in the conceptual framework. Use of anthropometric scores in such studies should be based on the new WHO growth reference. Further, determinants of malnutrition at the household level such as the reasons for intra-household discrimination in allocation of food and whether gender differences in nutrition status are an underlying pathway for excessive girl mortality in rural Thatta needs examination.

\section{Competing interests}

The author(s) declare that they have no competing interests.

\section{Authors' contribution}

RN participated in the design of survey, conceived and designed the study, performed the literature review and data analysis and drafted the

manuscript. WCH participated in the study design, data interpretation and in revising the paper critically for substantial intellectual content. Both the authors read and approved the final manuscript.

\section{Acknowledgements}

Authors are thankful to Assistant Professor lqbal Azam of the Aga Khan University for providing technical assistance during data organization, to Late Professor Lim Meng Kin of the National University of Singapore for his advice on interpretation of findings and to the journal reviewers for their constructive comments. We gratefully acknowledge the contribution of field investigators, supervisors and participants in data collection process. The analysis and opinions in this paper are those of the authors and not of their employing or funding agencies. We declare that there is no conflict of interest between the authors.

\section{Funding}

Funding support for the survey came from International Development Research Centre (IDRC), Canada.

Received: 30 July 2015 Accepted: 15 December 2015

Published online: 21 December 2015

\section{References}

1. Pelletier DL, Frongillo EAJ, Schroeder DG, Habicht JP. The effects of malnutrition on child mortality in developing countries. Bull World Health Organ. 1995;73(4):443-8.

2. Rice AL, Sacco L, Hyder A, Black RE. Malnutrition as an underlying cause of childhood deaths associated with infectious diseases in developing countries. Bull World Health Organ. 2000;78(10):1207-21.

3. Berkman DS, Lescano AG, Gilman RH, Lopez SL, Black MM. Effects of stunting, diarrhoeal disease, and parasitic infection during infancy on cognition in late childhood: a follow-up study. Lancet. 2002;359:564-71.

4. Global framework for action. 2006. Ending child hunger and under-nutrition initiative. In: World Food Programme and UNICEF. 2006; 16.

5. A Global Hunger Index: The challenge of hidden hunger. Washington, U.S.A. In: International food policy research institute, 2014; Chapter 02, 16.

6. World Health Organization. 2015. National Landscape Information System (NLIS), Country Profile. http://apps.who.int/nutrition/landscape/report. aspx?iso=pak

7. National Nutrition Survey 2011, Planning Commission, Planning and Development Division, Government of Pakistan, Aga Khan University, Pakistan, UNICEF Pakistan. 2011: 35

8. World Health Organization. World Health Statistics 2010. Geneva: World Health Organization; 2010. p. 106-7.

9. Dey I, Chaudhuri RN. Gender inequality in nutritional status among under five children in a village in Hooghly district, West Bengal. Indian J Public Health. 2008;52(4):218-20.

10. The Global Gender Gap Report, 2011. World Economic Forum. Geneva, Switzerland 2011.

11. The Global Gender Gap Report, 2014. World Economic Forum. Geneva, Switzerland 2014.

12. Baig-Ansari N, Rahbar MH, Bhutta ZA, Badruddin SH. Child's gender and household food insecurity are associated with stunting among young 
Pakistani children residing in urban squatter settlements. Food Nutr Bull. 2006;27(2):114-27.

13. Hazarika G. Gender differences in children's nutrition and access to health care in Pakistan. J Dev Stud. 2000;37:73-92.

14. Shah SM, Selwyn BJ, Luby S, Merchant A, Bano R. Prevalence and correlates of stunting among children in rural Pakistan. Pediatr Int. 2003;45:49-53.

15. de Onis M, Habicht JP. Anthropometric reference data for international use: recommendations from a World Health Organization Expert Committee. Am J Clin Nutr. 1996;64:650-8.

16. WHO Multicentre Growth Reference Study Group. WHO Child Growth Standards based on length/height, weight and age. Acta Paediatr. 2006:450:76-85.

17. WHO Multicentre Growth Reference Study Group. Assessment of differences in linear growth among populations in the WHO Multicentre Growth Reference Study. Acta Paediatr. 2006;450:56-65.

18. Nuruddin R, Meng-Kin L, Hadden WC, Azam I. Comparison of estimates of under-nutrition for pre-school rural Pakistani children based on the WHO standard and the National Center for Health Statistics NCHS reference. Public Health Nutr. 2009;12(5):716-22.

19. de Onis M, Onyango AW, Borghi E, Garza C, Yang H. WHO Multicentre Growth Reference Study Group. Comparison of the World Health Organization (WHO) Child Growth Standards and the National Center for Health Statistics WHO international growth reference: implications for child health programmes. Public Health Nutr. 2006;9(7):942-7.

20. Abul-Fadl A, Bagchi K, Cheikh IL. Practices in child growth monitoring in the countries of the Eastern Mediterranean Region. East Mediterr Health J. 2010;16(2):194-201.

21. Mosley WH, Chen LC. An analytic framework for the study of child survival in developing countries. Popul Dev Rev. 1984;10:25-45.

22. UNICEF. Strategy for improved nutrition of children and women in developing countries. East Asia \& Pacific Regional Office. Health and Nutrition Working Paper. New York: United Nations Children's Fund. Nutrition Section; 2003. p. 7.

23. Noorani NA, Sohani SB, Omair A, Amir Ali N, Khwaja RS, Jan A, Shah S. Thatta Health System Research Project, Phase III Year 1 Report In. Karachi: The Aga Khan University, Department of Health, Sindh and International Development Research Centre, Canada. 1993-94: B1 1-5.

24. Noor Ali R, Hirani A, Hussain HF, Amir Ali N, Jan A. Thatta Health System Research Project, Phase III Year 2 Report. Research Information System. In. Karachi: The Aga Khan University, Karachi, Department of Health, Sindh and International Development Research Centre, Canada. 1994-95: B1 1-16.

25. Report on the status of millennium development goals, Sindh. United Nations Development Programme Pakistan and Government of Sindh. 2012: 2, 12

26. UNICEF. District-based Multiple Indicators Cluster Survey (MICS) 2003-04 Karachi: Planning and Development Department, Federal Bureau of Statistics and UNICEF (courtesy: the World Bank); 2005. p. 68, 91, 92,94,95.

27. Pakistan Social and Living Standards Measurement Survey (PSLM) 2012-13. In: FBoS (ed). Statistics Division, Government of Pakistan, Statistics Division, Pakistan Bureau of Statistics, Islamabad, 2014.

28. Nuruddin R, Hadden WC, Petersen MR, Lim MK. Does child gender determine household decision for health care in rural Thatta, Pakistan? J Public Health. 2009;31(3):389-97.

29. Population Welfare Department. District profiles. In: Governtment of Sindh. 2005.

30. Pakistan Demographic and Health Survey 2012-13. National Institute of Population Studies Islamabad, Pakistan and USAID. Chapter 11; 165-7.

31. Nuruddin R, Meng Kin L, Hadden WC, et al. Maternal chronic ill health negatively affects child survival in a poor rural population of Pakistan. World Health Popul. 2007;9(3):27-35.

32. Pakistan Social and Living Standards Measurement Survey (PSLM). In: FBoS (ed). Statistics Division, Government of Pakistan. 2004-05.

33. Daniel WW. Biostatistics: a foundation analysis in the health sciences. 5th ed. Hoboken: John Wiley; 1987.

34. de Onis M, Blossner M. WHO Global Database on Child Growth and Malnutrition. Organization: Geneva. World Health; 1997. p. 1-65.

35. de Onis M, Onyango AW, Borghi E, Garza C, Yang H. WHO Multicentre Growth Reference Study Group. Comparison of the World Health Organization (WHO) Child Growth Standards and the National Center for Health Statistics / WHO international growth reference: implications for child health programmes. Public Health Nutr. 2006;9:942-7.
36. Petersen MR, Deddens JA. A comparison of two methods for estimating prevalence ratios. BMC Med Res Methodol. 2008;28(8):9.

37. SAS. Statistical Analysis System. Version 9.1. North Carolina: SAS Institute Inc. USA, 2002-2003.

38. Deddens JA, Petersen MR, Lei X. Estimation of Prevalence Ratios when PROC GENMOD Does Not Converge. SUGI Proceedings, 2003.

39. Deddens JA, Petersen MR. Approaches for estimating prevalence ratios. Occup Environ Med. 2008;65:501-6.

40. Pakistan Millennium Development Goals, 2013. Ministry of Planning, Development and Reform. Planning Commission, Government of Pakistan. Islamabad. 2013: 18.

41. Moestue H. Can anthropometry measure gender discrimination? An analysis using WHO standards to assess the growth of Bangladeshi children. Public Health Nutr. 2008;12:1085-91.

42. Moestue H, de Pee S, Hall A, Hye A, Sultana N, Ishtiaque MZ, et al. Conclusions about differences in linear growth between Bangladeshi boys and girls depend on the growth reference used. Eur J Clin Nutr. 2004;58:725-31.

43. Dancer D, Rammohan A, Murray SD. Infant mortality and child nutrition in Bangladesh. Health Econ. 2008;17:1015-35.

44. Ricci JA, Becker S. Risk factors for wasting and stunting among children in Metro Cebu, Philippines. Am J Clin Nutr. 1996;63:966-75.

45. Arya A, Devi R. Influence of maternal literacy on the nutritional status of preschool children. Indian J Pediatr. 1991;58:265-8.

46. Wamani H, Tylleskar T, Astrom AN, Tumwine JK, Peterson S. Mothers' education but not fathers' education, household assets or land ownership is the best predictor of child health inequalities in rural Uganda. Int J Equity Health. 2004:3:1-8.

47. Hong R, Banta JE, Betancourt JA. Relationship between household wealth inequality and chronic childhood under-nutrition in Bangladesh. Int J Equity Health. 2006;5:15.

48. Hong R, Mishra V. Effect of wealth inequality on chronic under-nutrition in Cambodian children. J Health Popul Nutr. 2006:24:89-99.

49. Basu AM. How pervasive are sex differentials in childhood nutritional levels in South Asia? J Soc Biol. 1993;40:25-37.

50. Filmer D, King EM, Pritchett L. Gender Disparity in South Asia: Comparisons between and within Countries. Washington, D.C: World Bank; 1998. p. 8.

51. Choudhury KK, Hanifi MA, Rasheed S, Bhuiya A. Gender inequality and severe malnutrition among children in a remote rural area of Bangladesh. J Health Popul Nutr. 2000;18:123-30.

52. Rousham EK. Socio-economic influences in gender inequalities in child health in rural Bangladesh. Eur J Clin Nutr. 1996;50:560-4.

53. Pande RP. Selective gender differences in childhood nutrition and immunization in rural India: The role of siblings. Demography. 2003:40:395-418.

54. Gorstein J. Assessment of nutritional status: effects of different methods to determine age on the classification of under nutrition. Bull World Health Organ. 1989;67:143-50.

\section{Submit your next manuscript to BioMed Central and we will help you at every step:}

- We accept pre-submission inquiries

- Our selector tool helps you to find the most relevant journal

- We provide round the clock customer support

- Convenient online submission

- Thorough peer review

- Inclusion in PubMed and all major indexing services

- Maximum visibility for your research

Submit your manuscript at www.biomedcentral.com/submit 